\title{
COMMENTS
}

\section{Creating a new university-education system to promote Agriculture Green Development}

\author{
Fusuo ZHANG $(\bowtie){ }^{1}$, Weichun DONG ${ }^{2}$, Jianqiang LI $^{3}$ \\ 1 National Academy of Agriculture Green Development, Key Laboratory of Plant-Soil Interactions (Ministry of Education), \\ College of Resources and Environmental Sciences, China Agricultural University, Beijing 100193, China \\ 2 Education Committee of China Association of Agricultural Science Societies, Magazine Office of China Agricultural Education, \\ Nanjing Agricultural University, Nanjing 210095, China \\ 3 The National Steering Committee for the Education of Agricultural Professional Degree Postgraduates, the Agricultural and Forestry \\ Committee of the Chinese Academic Degree and Graduate Education Association, China Agricultural University, Beijing 100193, China
}

In September 2019, in a letter to the principals and relevant experts of agriculture-related universities in China, President Xi Jinping pointed out that China's modernization is inseparable from agricultural and rural modernization. The key to agricultural and rural modernization lies in science and technology and talents. A new generation of global scientific, technological and industrial revolutions is now underway. With the extensive penetration and integration of biotechnology, information technology, engineering technology, management science and agricultural science, new disciplines are fast emerging, providing unprecedented opportunities for agricultural scientific and technological progress and agro-industrial development.

In the face of this great change, remolding the old disciplinary system and constructing a "new disciplinary system of agricultural sciences" has become an urgent and primary target for reform of higher agricultural education in the new era. The new disciplinary system of agricultural sciences should pay much attention to food security, rural revitalization, ecological civilization, human health and social sustainability. Because of the all-pervasive nature of the global challenge, students must be trained to allow cross disciplinary initiatives to be developed. Agricultural universities need to build new systems of talent cultivation in higher agricultural education, science and technology innovations as well as social services. The reform will allow university education to really support economic, industrial and social development of "The Great Times".

In the past 40 years of economic reform, China has made great strides in promoting agricultural development, where higher agricultural education has played a pivotal supporting role. Moreover, the construction of agriculturerelated disciplines and the cultivation of graduates have also developed rapidly. The structures and systems for cultivating senior agricultural talents are increasingly effective. Developments include: two levels of degrees, i.e., master's and doctoral degrees, as well as two types of degrees, i.e., academic (Master of Agronomy, Doctor of Agronomy) and professional (Master of Agriculture, Master of Forestry, Master of Veterinary Medicine, Doctor of Veterinary Medicine) degrees. More than 300000 university students have graduated with at least an agriculturallyrelated master's degree in China since reform and the "opening up" policy was implemented in 1978, and more than 30000 graduate each year with a master's degree in agriculture, a master's degree in agronomy, or a doctorate in agronomy, providing the talent pool and making great contributions to the development of the agricultural industry and the economic boom.

However, facing the transformation of agricultural systems and rapid development of green agriculture in the new era, the system of training, scale, and quality of current agricultural talent cultivation in China are far from fulfilling the requirements of the nation. The lack of an effective interdisciplinary talent cultivation model is the essential bottleneck restricting China's Agriculture Green Development (AGD). In the context of the national comprehensive

Received January 6, 2020

Correspondence: zhangfs@cau.edu.cn

(C) The Author(s) 2020. Published by Higher Education Press. This is an open access article under the CC BY license (http://creativecommons.org/licenses/by/4.0) 
implementation of green development and rural revitalization strategies, the previous model, which focused on cultivating academic talents, must be refocused upon cultivating both academic and practice-oriented talents. Furthermore, it is necessary to accelerate the cultivation of versatile talents by integrating agricultural industry and education, and by implementing interdisciplinary and comprehensive education. Transformation is urgently needed in the following areas, and is necessary to change the emphasis of our efforts: (1) from solving the problem of providing people with more calories in their diets through increasing food production and supply solely, to exploring a multi-objective synergy with food and nutrition security, human health, and resources and environment sustainability; (2) from focusing on only the issue of single processes in agricultural industry, to an increased emphasis on the whole-industry-chain through integrating the primary, secondary, and tertiary industries, sustainable food systems, resource and environment, and peoples' well-being for a better life; and (3) from focusing on resolving local agricultural issues to addressing global challenges towards building a community of shared future for mankind.

In order to realize these goals, the Ministry of Education proposed eight major actions for the development of the "new disciplinary system of agricultural sciences", involving cultivation of new talents, optimization of majors, curriculum reform and innovation, construction of practice bases, cultivation of high-quality teachers, enhancement of cooperative education, improvement of quality standards, and a deepening of openness and cooperation. Moreover, the new discipline of knowledge exchange $(\mathrm{KE})$ is becoming more and more important with the reform of the disciplinary system. Therefore, it is crucial to promote training, nurturing, and mentoring the new generation of agricultural scientists who would have the knowledge, skills, creativity, and dedication to advance the fields.

For many years, China Agricultural University has focused on resolving key problems in the front line of agricultural production and at the forefront of the industry by integrating science and technology innovation, talent training and social services. The university has pioneered a new model of "Talent cultivation based on the system of Science and Technology Backyard (STB)", thus providing beneficial experience and successful examples for the construction of the "new disciplinary system of agricultural sciences". The new model enables graduate students to place themselves in the big platform of agricultural production practice and industrial development as well as the main battlefield of national economic construction and development, in order to innovate science and technology and cultivate versatile talents with a better understanding of agriculture and a passion for rural development and helping farmers, as well as combining theoretical and practical expertise. The KE in the STB model not only improves the quality of training graduate students but also enhances the benefits to farmers and other members of the food system. Recently, in collaboration with Wageningen University in the Netherlands, China Agricultural University is developing a new model for the "T-type" agricultural doctorate cultivation system that can integrate broad multidisciplinary knowledge with in-deep research. The new model aims to cultivate outstanding talents who can not only address the challenges at the international frontiers of scientific research, but also break through technical bottlenecks restricting the agricultural industry in order to promote sustainable development. Moreover, an innovative PIE project (training PhD students-doing social Impact research-seeking new Education model) has been launched, and it explores a novel way of constructing the "new disciplinary system of agricultural sciences" in Chinese higher education in agriculture. Furthermore, elsewhere in the world, relevant to this thinking, there are good examples of novel agricultural education systems, e.g., joint on line agricultural education with the industry in the UK as described by Davies et al. in this issue (https://doi.org/10.15302/J-FASE-2019299). Here, students all over the world are already working in industry and taking interdisciplinary courses on line.

in addition, Nanjing Agricultural University (NAU) has proposed the talent cultivation concept of "World Vision, Chinese Spirit and NAU Quality", and established a "general-professional combined" core curriculum system for agricultural sciences, as well as an education system focusing on the challenges developing in "a big country with key issues of agriculture, rural areas and farmers". The curriculum and education systems cultivate students' abilities in philosophical thinking, scientific thinking, interdisciplinary understanding, and cross-cultural communication, from the perspective of six aspects including literature and art, historical research, social analysis, philosophical methods, scientific exploration, and foreign culture. Agricultural universities in China should strive to promote the overall cultivation of outstanding agricultural talents, and actively explore the development of the "new agricultural science" education system.

The construction of "new disciplinary system of agricultural sciences" refers to the development and restructuring of the agricultural higher education system for the new era, to meet the strategic needs of poverty alleviation, rural revitalization, ecological civilization, and a beautiful and happy China. The "new agricultural science" must aim to address the problems of agricultural production, livehood, and ecology, and it must be in line with the tide of the new technological revolution and reform, thereby promoting deep cross-integration of agricultural sciences and green development, enhancing eco-development forces, and contributing to construction of a more environmentallysustainable China with blue skies, green mountains, clean water, safe food, and a peaceful life.

The innovation fields of the "new agricultural science" involve green development, smart agriculture, 
biotechnology, nutrition and health, ecological environment, rural construction, global agriculture, etc. By implementing the development concepts of innovation, coordination, greenness, openness and sharing, the reform of "new agricultural science" will address the challenges of the scientific and technological revolution and agricultural transformation, to support the "green development" and "village revitalization" strategies. The novel model for China's higher agricultural education can also help us address the growing challenge of the climate emergency where global practices in land use and in food and farming must be reformed if we are to limit some of the worst of the predicted consequences. 